\title{
Rio de Janeiro: rumo a uma nova região metropolitana?
}

\author{
Rio de Janeiro: moving toward \\ a new metropolitan region?
}

Joseane de Souza Denise Cunha Tavares Terra

\section{Resumo}

No estado do Rio de Janeiro, os aglomerados de Cabo Frio, Macaé-Rio das Ostras e Campos dos Goytacazes foram considerados, pelo IBGE (2017), como casos especiais a serem acompanhados, tendo em vista estarem presentes algumas características "relevantes da urbanização brasileira". A nosso ver, tais características podem estar relacionadas a um incipiente processo de metropolização, principalmente quando se considera que, na atualidade, o Brasil abriga distintos padrões de metrópole e que nem toda região metropolitana tem uma metrópole como polo. Este artigo tem como objetivo refletir sobre o processo que está em curso nesses aglomerados, a fim de verificar se apresenta características de um processo de metropolização. Serão considerados alguns indicadores demográficos como densidade, migrações e pendularidade interaglomerados.

Palavras-chave: região metropolitana; aglomerados urbanos; indicadores demográficos; Rio de Janeiro.

\begin{abstract}
In the state of Rio de Janeiro, the clusters of Cabo Frio, Macaé-Rio das Ostras and Campos dos Goytacazes were considered, by the Brazilian Institute of Geography and Statistics (2015), as special cases to be followed in view of the presence of some "relevant characteristics of the Brazilian urbanization". In our view, such characteristics may be related to an incipient process of metropolization, especially when we take into account that, today, Brazil has different patterns of metropolises, although not every metropolitan region has a metropolis as a pole. This article aims to reflect on the process that is underway in these clusters, to verify if it presents characteristics of a process of metropolization. Some demographic indicators such as density, migration and inter-cluster pendulum will be considered.
\end{abstract}

Keywords: metropolitan region; urban clusters; demographic indicators; Rio de Janeiro. 


\section{Introdução}

0 processo de urbanização tem-se tornado cada vez mais complexo, abrindo espaço, inclusive, para o surgimento de novas urbanidades. Assim, há novas aglomerações urbanas - metropolitanas e não metropolitanas - que devem ser acompanhadas por estarem refletindo processos de divisão técnica e territorial do trabalho, cujo efeito é maior integração entre municípios espacialmente contíguos ou não. No estado do Rio de Janeiro, os aglomerados de "Cabo Frio", "Macaé-Rio das Ostras" e "Campos dos Goytacazes" foram considerados, pelo IBGE (Brasil/IBGE, 2015), como casos especiais a serem acompanhados, tendo em vista estarem presentes algumas características "relevantes da urbanização brasileira" (ibid., p. 68). A nosso ver, tais características podem estar relacionadas a um incipiente processo de metropolização, principalmente quando se considera que, a partir do final da década de 1980, o Brasil passou a abrigar distintos padrões de metrópole e que nem toda região metropolitana tem, obrigatoriamente, uma metrópole como polo.

Este artigo tem como objetivo refletir sobre o processo que está em curso nesses aglomerados, no sentido de compreender se ele apresenta características de um processo de metropolização.

Para tanto, além desta Introdução, o artigo conta com outras 6 seções. Na segunda seção, apresentam-se as características gerais da urbanização brasileira a partir dos anos 1930 e discutem-se as mudanças mais recentes nas características do processo de urbanização brasileira, buscando-se explicitar os fatores determinantes desse processo, na atualidade.

Na terceira seção, discutem-se, à luz da literatura, os conceitos, assim como os critérios que, no plano teórico, definem uma Região Metropolitana. Ainda nessa seção, discute-se o processo de criação das novas regiões metropolitanas no Brasil, pós-Constituição Federal de 1988.

$\mathrm{Na}$ quarta seção, analisa-se o processo de complexificação da rede urbana, ou seja, da rede de cidades do Rio de Janeiro, sob a ótica dos aglomerados urbanos. Nesse sentido, apresentamos, então, as principais características da Região Metropolitana do Rio de Janeiro (RMRJ) e sua relação, no período 2000-2010, com os demais aglomerados urbanos do estado, a fim de compreendermos o seu papel no processo de interiorização do crescimento. Para tanto, consideramos as informações censitárias (IBGE, 2010) relativas às migrações intraestaduais subdivididas, para efeitos analíticos, em "migração intra-aglomerados" e "migração interestadual, exclusive intra-aglomerados".

Na quinta seção, buscou-se, na análise de alguns indicadores demográficos, compreender se há ou não um processo (ainda que incipiente) de metropolização que envolve três aglomerados urbanos do litoral norte, a saber: Cabo Frio, Campos dos Goytacazes e Macaé-Rio das Ostras.

Por fim, são apresentadas, na sexta seção, as considerações finais, que não apresentam conclusões definitivas, mas, antes, buscam suscitar questões que devem ser mais aprofundadas pelos pesquisadores dessa área e, na sétima seção, as referências utilizadas para a realização deste artigo. 


\section{Mudanças nas características do processo de urbanização brasileiro}

0 nosso processo de urbanização foi distinto daquele ocorrido nos países mais avançados, que apresentaram um processo mais lento, mas com uma melhor distribuição e equidade em relação ao verificado nos países subdesenvolvidos. Segundo Cano (1989), o início do nosso processo de urbanização apresentou dois importantes momentos: o primeiro relacionado ao período de nossa formação colonial, com as cidades voltadas aos interesses imediatos de Portugal, portanto voltado "para fora". Posteriormente, com a proclamação da independência e uma economia agrário-exportadora, as cidades passaram a apresentar um crescimento voltado "para dentro", fortalecendo e ampliando as antigas concentrações urbanas, sem preocupação com a necessidade de integração do mercado nacional, gerando um sistema urbano complexo e com grande "heterogeneidade estrutural".

Foi somente após a década de 1930 que surgiram condições políticas e organizacionais que permitiram impulsionar o processo de industrialização, por substituição de importações. 0 apoio do governo e o crescimento do mercado interno proporcionaram a formação de uma nova lógica econômica e territorial. No entanto, a real inversão do local de moradia dos brasileiros aconteceu entre as décadas de 1940 e 1980, quando a população urbana se multiplicou por sete vezes e meia, enquanto a população brasileira triplicou (Santos, 2005).

Esse processo pode ser explicado, em grande parte, pelo intenso fluxo migratório rural-urbano. Com a industrialização voltada para o consumo interno, há uma crescente demanda por trabalhadores nas cidades, o que incentiva a vinda de migrantes, especialmente do Norte e do Nordeste. São Paulo, a principal cidade industrial do Brasil, recebeu um significativo contingente de migrantes nordestinos. Além disso, a desestruturação da economia rural, voltada para a produção de bens alimentares destinados ao abastecimento do mercado externo, em especial o café, estava em declínio devido à crise de 1929, liberando mão de obra para as novas ocupações urbanas.

Segundo Brito, Horta e Amaral (2001), o auge do crescimento da população urbana ocorreu entre 1950 e 1980, e, até 1980, o padrão predominante era o de concentração em cidades grandes, com população superior a 500 mil habitantes. Entre os anos 1970 e 1980, quase metade da população urbana vivia em aglomerações metropolitanas. Após 1980, ocorre uma desconcentração relativa, favorecendo as cidades de porte médio, entre 100 e 500 mil habitantes, que passam a crescer com mais intensidade do que as cidades grandes. Entre os fatores que contribuíram para a redução do crescimento das aglomerações metropolitanas se encontram: a) redução do nível de fecundidade; e b) redução da oferta de emprego devido à crise econômica. A contribuição do núcleo para o crescimento do aglomerado também declina a partir da década de 1980, tendo, desde então, as periferias galgado o principal papel pelo seu crescimento.

Mais recentemente, a urbanização tem-se diversificado, tornando-se mais complexa, tendo em vista a importância dada ao capital intelectual. A produção não material torna a divisão do trabalho mais intensa e heterogênea, 
ocasionando maior diferenciação entre cidades e regiões. Por isso, Santos (2005) nos adverte que não podemos tratar mais a rede urbana como no início do nosso processo de urbanização, segundo a hierarquia de tamanho e de funções, pois as cidades não se relacionam mais dessa forma. Devido a amplitude e diversidade da divisão territorial do trabalho, fortalecida pelo moderno sistema de transporte e de comunicações, surgem as "metrópoles incompletas", cada uma oferecendo tarefas distintas. Foi-se o tempo em que a indústria era a principal força para dotar uma área de centralidade. Hoje a centralidade de um lugar é derivada da sua capacidade de produção, coleta e classificação de informações e do uso que se faz delas, a partir de seus interesses, bem como do contexto de elevada competitividade e fluidez do capital financeiro, conforme descreve Carlos (2009, p. 303):

[...] os processos contemporâneos se realizam a partir da integração-desintegração dos espaços em redes mundiais como necessidade e produto da realização da reprodução capitalista num contexto de alta competitividade e fluidez do capital financeiro. Desse modo, o processo de urbanização metropolitana revela a produção de um "novo espaço", isso porque o capitalismo se expandiu e, ao se realizar, tomou o mundo. Esse é o momento da redefinição da metrópole, de sua explosão, da extensão das periferias, da reprodução do espaço num outro patamar em razão dos novos conteúdos do estágio globalizado da economia das relações e dos graus de dependência das áreas entre si.

Analisando a metrópole de São Paulo, no contexto da urbanização contemporânea, Carlos (ibid.) identificou que o capital se reproduz a partir de três setores dinâmicos da economia, revelando os novos conteúdos do nosso atual processo de urbanização: 1) capital financeiro, que é aplicado no setor imobiliário com a construção de edifícios voltados para o setor de aluguel e que acolhem os novos setores econômicos modernos que se instalam nas metrópoles; 2) atividade turística voltada para negócios, 0 denominado "turismo de negócios", sendo a infraestrutura hoteleira instalada na área de expansão do centro moderno da metrópole. Trata-se de uma nova lógica de reprodução do capital financeiro, que inclui o solo urbano como possibilidade de sua reprodução; 3) o narcotráfico, que, para se reproduzir, normatiza o uso e o acesso do espaço, produzindo o seu espaço. Esses três setores econômicos utilizam o espaço, que aparece como condição necessária ao processo de reprodução do capital, produzindo um "novo espaço", um espaço que se torna produtivo e a partir do qual a reprodução do capital vai se realizar superando as crises de acumulação, típicas do capitalismo.

No entanto, nem todas as metrópoles brasileiras apresentam esses conteúdos típicos da urbanização contemporânea, com os três setores econômicos justapostos e integrados ao mercado, sob as estratégias da globalização.

\section{Conceito de região metropolitana: da mensuração à definição por decreto}

Comumente definida como área urbana de alta densidade demográfica, uma Região Metropolitana (RM) é, para Castells (2000, p. 53), 
qualquer coisa a mais do que um aumento de dimensão e de densidade dos aglomerados urbanos existentes. [...] o que distingue esta nova forma [espacial] das precedentes não é só seu tamanho (que é a consequência da sua estrutura interna) mas também a difusão no espaço das atividades, das funções e dos grupos, e sua interdependência segundo uma dinâmica social amplamente independente da ligação geográfica.

Segundo Moreira (1989 apud Carmo, 2004, p. 77), uma região metropolitana "pressupõe um fato social e econômico cuja essência é a metrópole, esta, o polo de atração e/ou dominação de um grande espaço de produção e consumo", entendendo-se por metrópole "uma cidade mãe (área urbana de um ou mais municípios) que exerce forte influência sobre o seu entorno, polarizando em si complexidade funcional e dimensões físicas que a destacam numa rede de cidades e no cenário regional" (Freitas, 2009, p. 45). Nesse aspecto, Firkowisk (2012) e Costa (2013) chamam a nossa atenção para o fato de que nem toda RM tem como cidade polo uma metrópole. Esta, definida por Firkowisk (2012, p. 37) como sendo

A grande cidade que possui funções superiores de comando e gestão e articuladas à economia global, sendo a porta de entrada dos fluxos globais no território nacional, onde se ancoram interesses internacionais e de onde partem, para o território nacional, vetores de modernidade e complexidade.

Para Braga e Carvalho (2004, p. 8), região metropolitana é "um aglomerado urbano composto por vários municípios administrativamente autônomos, mas integrados física e funcionalmente, formando uma mancha urbana praticamente contínua".

No Brasil, a criação de regiões metropolitanas foi prevista, pela primeira vez, no artigo 157 §10 da Constituição Federal de 1967:

A União, mediante lei complementar, poderá estabelecer regiões metropolitanas, constituídas por Municípios que, independentemente de sua vinculação administrativa, integrem a mesma comunidade socioeconômica, visando à realização de serviços de interesse comum.

0 artigo 164 da Constituição Federal de 1969 (Brasil, 1969) manteve a institucionalização de regiões metropolitanas como sendo de responsabilidade do governo federal. Segundo Hotz (2000, p. 92),

Verifica-se, na leitura destes textos [Constituição Federal de 1967 e de 1969], que o legislador do autoritarismo tratou de circunscrever o fato metropolitano, do ponto de vista da autoridade, à União, único poder autorizado a instituir unidades regionais da espécie e, do ponto de vista do alcance da ação metropolitana, apenas à realização de serviços de interesse comum, deixando de lado outras categorias que poderiam conotar esta ação.

Então, com o objetivo de integrar o território nacional (Barreto, 2012), através da lei complementar 14/1973 foram criadas, pelo governo federal, as oito primeiras regiões metropolitanas do país - São Paulo/SP; Belo Horizonte/MG; Porto Alegre/RS; Curitiba/PR; Salvador/ BA; Recife/PE; Fortaleza/CE; e Belém/PA - e, em 1974, pela lei complementar de número 20, a Região Metropolitana do Rio de Janeiro. 
Segundo Moura, Libardi e Barion (2006, p. 130), o processo de institucionalização dessas RMs "fez parte da política nacional de desenvolvimento urbano, relacionada à expansão da produção industrial e à consolidação das metrópoles como locus desse processo".

Como características marcantes, os autores identificam: a) o fato de se tratar de centros nacionais e de sua área de polarização direta; b) o núcleo da RM - metrópole - coincidir com a própria capital estadual; e c) o objetivo de constituir uma única unidade de planejamento, visando à realização de serviços comuns.

0 quadro metropolitano brasileiro permaneceu inalterado até 1990, momento a partir do qual novas RMs foram instituídas, como uma consequência da Constituição Federal de 1988, que transferiu para os Estados o poder de criação, por lei complementar, dessas unidades regionais. Além de descentralização da criação de RMs, o texto constitucional avançou também na ampliação da tipologia de unidades regionais, com a formalização de duas novas categorias: aglomerações urbanas e microrregiões (Hotz, 2000).

Uma aglomeração (ou concentração) urbana é formada por municípios isolados e por arranjos populacionais com população superior a 100 mil habitantes (Figura 1), sendo considerada de médio porte aquela com população acima de 100 até 750 mil habitantes e de grande porte aquela com população superior a 750 mil habitantes (IBGE, 2015). Segundo Ipardes (2000 apud Moura, Libardi e Barion, 2006, p. 133), uma aglomeração urbana

corresponde a uma mancha contínua de ocupação constituída por mais de uma unidade municipal, envolvendo intensos fluxos intermunicipais com comutação diária, complementaridade funcional, agregadas por integração socioeconômica decorrente de especialização, complementação e/ou suplementação funcional. Pode ser derivada de periferização de um centro principal por sobre municípios vizinhos; da conurbação entre núcleos de tamanho equivalente ou não, mesmo sem periferia, polarizada por esses centros urbanos; da incorporação de municípios próximos, independentemente de continuidade de mancha, desde que mantenham relações intensas.

Para a identificação de um arranjo populacional, foram considerados os seguintes critérios:

Forte intensidade relativa dos movimentos pendulares para trabalho e estudo tal intensidade deve ser igual ou superior a 0,25 do índice de integração

Forte intensidade absoluta dos movimentos pendulares para trabalho e estudo - quando o volume absoluto de pessoas que se deslocam para trabalho $\mathrm{e}$ estudo, entre A e B, é igual ou superior a 10000 pessoas ou

Contiguidade das manchas urbanizadas - quando a distância entre as bordas das manchas urbanizadas principais de dois municípios é de até $3 \mathrm{~km} .{ }^{1}$

Como se pode notar na Tabela 1, o IBGE (ibid.) identificou um total de 294 arranjos populacionais no Brasil, havendo enorme concentração nas regiões Sudeste e Sul. Nesses arranjos, residiam, em 2010, 106.782.428 habitantes, o que correspondia a $56 \%$ da população brasileira naquele período.

No mesmo estudo, o IBGE considerou que, entre as concentrações urbanas brasileiras, apenas 12 - a saber: São Paulo/SP; Rio de Janeiro/RJ; Belo Horizonte/MG; Recife/ PE; Porto Alegre/RS; Salvador/BA; Brasília/ 
DF; Fortaleza/CE; Curitiba/PR; Goiânia/GO; Belém/PA; e Manaus/AM - têm caráter metropolitano, muito embora sejam, atualmente, 70 o total de RMs institucionalizadas, localizadas principalmente nas regiões Nordeste (um total de 27, sendo 12 apenas no estado da Paraíba) e Sul (nesse caso há maior concentração em Santa Catarina, onde se localizam 10, entre as 20 RMs regionais), como se pode notar na Tabela 2.
Na região Sudeste, foram criadas as Regiões Metropolitanas de Vitória (1995), no Espírito Santo; do Vale do Aço (1998), em Minas Gerais; e da Baixada Santista (1996), de Campinas (2000), de Ribeiro Preto (2016), de Sorocaba (2014) e do Vale do Paraíba e Litoral Norte (2012), em São Paulo. Nessa macrorregião, o Rio de Janeiro é o único estado que não criou novas RMs, a partir da Constituição de 1988.

Tabela 1 - Brasil -

Número de arranjos populacionais e população residente total (2010)

\begin{tabular}{l|c|c|c|c|c}
\hline Grandes regiões & $\begin{array}{c}\text { Número } \\
\text { de arranjos } \\
\text { populacionais }\end{array}$ & $\begin{array}{c}\text { Distribuição } \\
\text { relativa } \\
\text { dos arranjos }\end{array}$ & População Total & $\begin{array}{c}\text { População } \\
\text { em arranjos }\end{array}$ & Total \\
\hline Norte & 17 & 5,8 & 15.864 .454 & 3.720 .357 & 23,5 \\
Nordeste & 56 & 19,0 & 53.081 .950 & 21.283 .027 & 40,1 \\
Sudeste & 112 & 38,1 & 80.364 .410 & 57.837 .929 & 72,0 \\
Sul & 85 & 28,9 & 27.386 .891 & 16.727 .072 & 61,1 \\
Centro-Oeste & 24 & 8,2 & 14.058 .094 & 7.214 .043 & 51,3 \\
Brasil & 294 & 100,0 & 190.755 .799 & 106.782 .428 & 56,0 \\
\hline
\end{tabular}

Fonte: Brasil/IBGE (2015, p. 31).

Tabela 2 - Brasil -

Número de Regiões Metropolitanas, segundo a macrorregião (2017)

\begin{tabular}{l|c|c}
\hline Grandes regiões & RMs & $\%$ \\
\hline Norte & 11 & 15,7 \\
Nordeste & 27 & 38,6 \\
Sudeste & 10 & 14,3 \\
Sul & 20 & 28,6 \\
Centro-Oeste & 2 & 2,9 \\
Brasil & 70 & 100,0 \\
\hline
\end{tabular}

Fonte: IBGE, 2017 (acesso em 5 de março). 
Dentre os fatores comumente usados para justificar a criação de tantas RMs, destacam-se: a necessidade de gestão regional e de planejamento compartilhado de algumas funções públicas de interesse comum (como transportes e saneamento socioambiental), através dos quais se espera promover a integração e o desenvolvimento regional e urbano; maior facilidade na resolução de problemas comuns; maior probabilidade de obtenção de recursos ou financiamentos externos e internos para investimentos em infraestrutura econômica, social e urbana; fortalecimento da região como um todo e de seus municípios, mais notadamente da "metrópole" no contexto da rede de cidades brasileiras; e o desejo do status "de metropolitano", ressaltando-se que eles não são excludentes entre si (adaptado de Costa, 2013; Barreto, 2012; Moura, Libardi e Barion, 2006; e Firkowiski, 2012).

É interessante observar o fato de que a ausência de diretrizes nacionais, aliada à multiplicidade conceitual e à autonomia estadual, resultou numa variedade de critérios - Barreto (2012), analisando o caso de Santa Catarina, considera haver ausência de critérios; Costa (2013, p. 325) argumenta que "RMs podem ser instituídas com base em qualquer critério ou mesmo sem a explicitação de critério algum" - e de definições de RMs nem sempre explicitadas nas constituições estaduais, como é o caso da Paraíba e de Santa Catarina, os estados com o maior número de RMs.

A título de exemplo, seguem as definições de RMs nos estados de São Paulo e de Minas Gerais, respectivamente, onde o fato metropolitano parece ser levado em conta, na institucionalização de novas RMs, justificando o número relativamente baixo de unidades metropolitanas criadas a partir da Constituição Federal de 1988:

[...] 0 agrupamento de Municípios limítrofes que assuma destacada expressão nacional, em razão de elevada densidade demográfica, significativa conurbação e de funções urbanas e regionais com alto grau de diversidade, especialização e integração socioeconômica, exigindo planejamento integrado e ação conjunta permanente dos entes públicos nela atuantes. (São Paulo, 1989, artigo $153 \S 1^{\circ}$ )

o conjunto de Municípios limítrofes que apresentam a ocorrência ou a tendência de continuidade do tecido urbano e de complementaridade de funções urbanas, que tenha como núcleo a capital do Estado ou metrópole regional e que exija planejamento integrado e gestão conjunta permanente por parte dos entes públicos nele atuantes. (Minas Gerais, 1990, artigo 45)

No caso específico de São Paulo, a afirmativa anterior é corroborada por Baeninger (2001, p. 322)

Havia se identificado, no processo de urbanização paulista, na década de 1970 , importantes polos de atração regional no interior: Campinas, Sorocaba, São José dos Campos, Ribeirão Preto, Bauru e São José do Rio Preto, os quais, já naquele momento, desempenharam papel fundamental no processo de desconcentração relativa da população. [...] 0 dinamismo gerado a partir do município-polo dessas regiões, extravasando os limites administrativos, passava a atingir municípios vizinhos, fossem como áreas de expansão industrial, de insumos industriais ou áreas para localização habitacional, resultando no crescimento e fortalecimento dos polos regionais. Desse modo, a dinâmica das 
cidades, já naquele momento, dependia muito mais de sua proximidade ou ligação com um polo do que de seu tamanho populacional.

Retomando a questão relativa aos critérios utilizados para a definição de uma região metropolitana, Firkowiski (2012) afirma que os mais utilizados são a contiguidade espacial e a integração socioeconômica entre municípios, o volume populacional, a densidade demográfica e os movimentos pendulares, muito embora os parâmetros de referência variem de um país para outro.

No contexto brasileiro, em muitos estados da federação, esses critérios sequer são levados em conta no momento de institucionalização das RMs, corroborando a afirmativa de que "ocorre uma dissociação entre o processo de metropolização e o de criação das regiões metropolitanas" (ibid., p. 21). Em outras palavras, a "absorção legal do termo 'região metropolitana' e a materialização da faculdade institucional de forma indiscriminada esvaziaram de conteúdo o conceito consagrado de região metropolitana na sua correspondência ao fato metropolitano" (Observatório, 2004, p. 8 apud Moura, Libardi e Barion, 2006, p. 133). Significa dizer que muitas dessas unidades pouco - ou nada - têm de metropolitano e que os legisladores desconhecem o fato de que uma verdadeira RM resulta de um processo e não meramente de uma legislação.

A Constituição do Estado de Minas Gerais traz, explicitamente em seu artigo 44, os critérios adotados naquele estado para a institucionalização de uma região metropolitana, são eles:

I - população e crescimento demográfico, com projeção quinquenal;
II - grau de conurbação e movimentos pendulares da população;

III - atividade econômica e perspectivas de desenvolvimento;

IV - fatores de polarização;

V - deficiência dos serviços públicos, em um ou mais municípios, com implicação no desenvolvimento da região.

Já, no caso de São Paulo, alguns dos critérios estão explicitados na própria definição do termo, enquanto outros permanecem subjetivos.

\section{Região metropolitana e aglomerados urbanos no Rio de Janeiro}

A Região Metropolitana do Rio de Janeiro (RMRJ) foi criada em 1974, um ano após a criação das demais oito regiões metropolitanas, pelo mesmo decreto do governo militar que fundiu o estado da Guanabara (antiga cidade do Rio de Janeiro) ao estado do Rio de Janeiro, criando o novo estado do Rio de Janeiro. $\mathrm{Na}$ época de sua criação, a RMRJ era constituída por 14 municípios e, ao longo do tempo, a sua composição foi-se alterando. Atualmente, é composta por 21 municípios: Rio de Janeiro, Belford Roxo, Cachoeiras de Macacu, Duque de Caxias, Guapimirim, Itaboraí, Itaguaí, Japeri, Magé, Maricá, Mesquita, Nilópolis, Niterói, Nova Iguaçu, Paracambi, Queimados, Rio Bonito, Seropédica, São Gonçalo, São João de Meriti e Tanguá.

A singularidade do processo de metropolização do espaço no Rio de Janeiro, segundo Davidovich (2001, p. 69), está ligada a diversos 
aspectos como: a) um perfil de concentração de população e de atividades que caracterizaram a cidade do Rio, desde o passado colonial e que se foi ampliando quando exerceu o papel de capital do País, de região portuária e, mais adiante, a posição metropolitana; b) a "ausência do imaginário de um pertencer coletivo das populações" por falta de "solidariedade territorial", que permanece nas identidades carioca e fluminense, que aponta a contradição entre 0 urbano da cidade do Rio de Janeiro e o isolamento do interior fragmentado e pouco populoso; c) quando sede do governo federal, foram adotadas políticas públicas ligadas a empreendimentos estatais e federais e setores beneficiados pela política de substituição de importações patenteando-se "a debilidade da iniciativa do empresariado privado carioca".

Segundo Azevedo e Lobo (2015), o fato de coexistirem duas unidades federativas no Rio de Janeiro dificultou tanto a formação de uma cultura mais solidária como a crença de que seria possível a organização de políticas públicas conjuntas metropolitanas, que resultassem em benefícios para todos. Não é por outro motivo que, após a iniciativa de criação da Fundação para o Desenvolvimento do Estado do Rio de Janeiro (Fundrem), ainda no governo da fusão, não houve nenhum outro esforço para formulação de novas institucionalidades de governança metropolitana, até recentemente, com a criação, em 2014, da Câmara Metropolitana.

Essa Câmara possui um grupo executivo de gestão metropolitana, responsável pela elaboração de uma nova base cartográfica dos 21 municípios da região; pela criação de um sistema de informações geográficas para a RMRJ; e pela coordenação da construção do Plano
Estratégico de Desenvolvimento Urbano Integrado (PDUI), também conhecido como Modelar a Metrópole.

Mesmo com a transferência de responsabilidade do governo federal para os estados no Rio de Janeiro, diferentemente da maioria dos estados brasileiros, não houve - pelo menos até o presente momento - criação de novas regiões metropolitanas.

Atualmente sua rede urbana, ou seja, sua rede de cidades é constituída por 92 municípios, sendo $38(41,3 \%)$ pertencentes a aglomerados urbanos não metropolitanos; 21 (22,8\%) ao aglomerado Rio de Janeiro, único com caráter metropolitano; ${ }^{2}$ e 33 (35,9\%) a municípios isolados (Tabela 3).

Em 2000 e 2010, praticamente 92\% da população estadual residia em aglomerados urbanos. No entanto, observamos, na Tabela 3, uma redistribuição relativa da população, no sentido de uma (incipiente) desconcentração urbano-metropolitana. Note-se que, em 2000, a população residente no aglomerado urbano Rio de Janeiro ${ }^{3}$ correspondia a $76,1 \%$ da população estadual e a $82,7 \%$ da residente em aglomerados urbanos, tendo esses valores se reduzido, em 2010 , para $74,7 \%$ e $81,3 \%$, respectivamente. Essa relativa - e incipiente - desconcentração urbano-metropolitana foi compensada pelo aumento da participação relativa das populações dos aglomerados de Araruama, Cabo Frio, Campos dos Goytacazes e Macaé.

Apesar de o aglomerado Rio de Janeiro apresentar a maior variação populacional absoluta - de 999.781 habitantes - e ter sido o maior responsável pelo incremento populacional absoluto do estado - $62,5 \%$ - seu ritmo de crescimento médio anual foi, entre 2000 e 2010, de apenas $0,88 \%$. 
Tabela 3 - Rio de Janeiro -

Rede urbana, segundo a modalidade de municípios (2010)

\begin{tabular}{|c|c|c|c|c|c|c|c|c|c|}
\hline \multirow{2}{*}{ Aglomerados urbanos } & \multicolumn{2}{|c|}{ Municípios } & \multicolumn{4}{|c|}{ População } & \multirow{2}{*}{$\begin{array}{c}\Delta \\
\text { Populacional } \\
\text { absoluta }\end{array}$} & \multirow{2}{*}{$\begin{array}{c}\text { Taxa de } \\
\text { crescimento } \\
\text { médio anual } \\
(2000-2010)\end{array}$} & \multirow{2}{*}{$\begin{array}{c}\text { Participação } \\
\text { relativa no } \\
\text { incremento } \\
\text { absoluto }\end{array}$} \\
\hline & $\mathbf{N}^{\circ}$ & $\%$ & 2000 & $\%$ & 2010 & $\%$ & & & \\
\hline Além Paraíba - Sapucaia ${ }^{1}$ & 1 & 1,1 & 17.157 & 0,1 & 17.525 & 0,1 & 368 & 0,21 & 0,02 \\
\hline Araruama & 2 & 2,2 & 97.892 & 0,7 & 134.859 & 0,8 & 36.967 & 3,26 & 2,31 \\
\hline Bom Jesus do Itabapoana ${ }^{2}$ & 1 & 1,1 & 33.655 & 0,2 & 35.411 & 0,2 & 1.756 & 0,51 & 0,11 \\
\hline Cabo Frio & 4 & 4,3 & 232.136 & 1,6 & 329.377 & 2,1 & 97.241 & 3,56 & 6,09 \\
\hline Campos dos Goytacazes & 2 & 2,2 & 434.850 & 3,0 & 496.478 & 3,1 & 61.628 & 1,33 & 3,86 \\
\hline Cordeiro-Cantagalo & 2 & 2,2 & 38.436 & 0,3 & 40.260 & 0,3 & 1.824 & 0,46 & 0,11 \\
\hline Itaocara & 2 & 2,2 & 31.021 & 0,2 & 33.112 & 0,2 & 2.091 & 0,65 & 0,13 \\
\hline Macaé & 5 & 5,4 & 218.480 & 1,5 & 382.321 & 2,4 & 163.841 & 5,76 & 10,25 \\
\hline Mendes - Eng. Paulo de Frontin & 2 & 2,2 & 29.453 & 0,2 & 31.172 & 0,2 & 1.719 & 0,57 & 0,11 \\
\hline Paty do Alferes - Miguel Pereira & 2 & 2,2 & 48.833 & 0,3 & 51.001 & 0,3 & 2.168 & 0,44 & 0,14 \\
\hline Petrópolis & 2 & 2,2 & 296.436 & 2,1 & 307.340 & 1,9 & 10.904 & 0,36 & 0,68 \\
\hline Resende & 4 & 4,3 & 152.113 & 1,1 & 177.937 & 1,1 & 25.824 & 1,58 & 1,62 \\
\hline Rio de Janeiro & 21 & 22,8 & 10.946 .617 & 76,1 & 11.946 .398 & 74,7 & 999.781 & 0,88 & 62,57 \\
\hline Santo Antônio de Pádua & 2 & 2,2 & 45.105 & 0,3 & 47.592 & 0,3 & 2.487 & 0,54 & 0,16 \\
\hline Três Rios - Paraíba & 3 & 3,3 & 117.310 & 0,8 & 126.696 & 0,8 & 9.386 & 0,77 & 0,59 \\
\hline Valença ${ }^{3}$ & 1 & 1,1 & 66.308 & 0,5 & 71.843 & 0,4 & 5.535 & 0,80 & 0,35 \\
\hline Barra Mansa - Volta Redonda & 3 & 3,3 & 432.297 & 3,0 & 458.335 & 2,9 & 26.038 & 0,59 & 1,63 \\
\hline AGLOMERADOS URBANOS & 59 & 64,1 & 13.238 .099 & 92,0 & 14.687 .657 & 91,9 & 1.449 .558 & 1,04 & 90,72 \\
\hline MUNICÍPIOS ISOLADOS & 33 & 35,9 & 1.154 .007 & 8,0 & 1.302 .272 & 8,1 & 148.265 & 1,22 & 9,28 \\
\hline TOTAL & 92 & 100,0 & 14.382.106 & 100,0 & 15.989 .929 & 100,0 & 1.597 .823 & 1,06 & 100,0 \\
\hline
\end{tabular}

Fonte: IBGE - censos demográficos de 2000 e 2010.

1. Esse aglomerado urbano é formado pelos municípios de Além Paraíba (MG) e Sapucaia (RJ). Nesta Tabela, as informações se restringem ao município pertencente ao estado fluminense.

2. Aglomerado constituído pelos municípios de Bom Jesus do Itabapoana (RJ) e Bom Jesus do Norte (ES). Nesta Tabela, as informações se restringem ao município pertencente ao estado fluminense.

3. Aglomerado constituído pelos municípios de Valença (RJ) e Rio Preto (MG). Nesta Tabela, as informações se restringem ao município pertencente ao estado fluminense.

Apenas Macaé-Rio das Ostras, Cabo Frio, Araruama, Resende e Campos dos Goytacazes apresentaram ritmo de crescimento médio anual acima da média estadual, estimada em 1,06\%, para o período 2000-2010. Entre tais aglomerados, três, localizados no litoral Norte, a saber: Cabo Frio (além do município que dá nome ao aglomerado, inclui os municípios de Armação dos Búzios, Arraial do Cabo, São Pedro da Aldeia e Saquarema); Campos dos
Goytacazes (São João da Barra); e Macaé- Rio das Ostras (Carapebus, Casimiro de Abreu e Conceição de Macabu) -, chamam a atenção, uma vez que foram conjuntamente responsáveis, entre 2000 e 2010 , por $20,2 \%$ do incremento populacional absoluto do estado e que a maioria de seus municípios forma, pelo menos a partir da década de 1980, a principal frente de interiorização do estado do Rio de Janeiro, como afirmam Souza e Frutuozo (no prelo). 
Como, no cenário atual, as migrações se tornaram a variável-chave para a definição das taxas de crescimento populacional, neste artigo serão analisadas as migrações intraestaduais para, por meio de sentidos e intensidades dos fluxos, identificarmos, não apenas os eixos de expansão urbana, mas as regiões que mais alimentam esse processo. Serão considerados apenas os movimentos intraestaduais, uma vez que, conforme apontaram Souza e Frutuozo (no prelo), no estado do Rio de Janeiro, "o papel das migrações interestaduais na definição dos eixos de expansão urbana, nas últimas décadas, é praticamente nulo. As migrações intraestaduais, de grande e crescente magnitude, são as que de fato definem a velocidade e a direção desse processo". Os resultados das migrações intraestaduais de última etapa, segundo os aglomerados urbanos e os municípios isolados do Rio de Janeiro, entre 2000 e 2010, encontram-se sumarizados na Tabela 4.

Tabela 4 - Rio de Janeiro -

Migrações intraestaduais de última etapa (2000-2010)

\begin{tabular}{|c|c|c|c|c|c|c|c|c|c|}
\hline \multirow{2}{*}{ Rede urbana fluminense } & \multicolumn{2}{|c|}{$\begin{array}{c}\text { Migração } \\
\text { intra-aglomerado }\end{array}$} & \multicolumn{7}{|c|}{ Migraçao Intraestadual (exclusive intra-aglomerado) } \\
\hline & Absoluto & $\%$ & I & $\% 1$ & E & $\% \mathrm{E}$ & Saldo & TLM & $\mathrm{I} / \mathrm{E}$ \\
\hline Além Paraíba - Sapucaia ${ }^{1}$ & 0 & 0,0 & 1.240 & 0,3 & 1.338 & 0,3 & -98 & $-0,6$ & 0,9 \\
\hline Araruama & 793 & 0,6 & 27.126 & 6,2 & 7.860 & 1,8 & 19.266 & 14,3 & 3,2 \\
\hline Bom Jesus do Itabapoana ${ }^{2}$ & 0 & 0,0 & 2.014 & 0,5 & 3.383 & 0,8 & -1.369 & $-3,9$ & 0,6 \\
\hline Cabo Frio & 11.059 & 3,4 & 64.370 & 14,8 & 18.863 & 4,3 & 45.507 & 13,8 & 2,5 \\
\hline Campos dos Goytacazes & 3.599 & 0,7 & 18.016 & 4,1 & 30.567 & 7,0 & -12.551 & $-2,5$ & 0,6 \\
\hline Cordeiro-Cantagalo & 1.254 & 3,1 & 3.011 & 0,7 & 4.113 & 0,9 & -1.102 & $-2,7$ & 0,8 \\
\hline Itaocara & 451 & 1,4 & 3.839 & 0,9 & 3.067 & 0,7 & 772 & 2,3 & 1,2 \\
\hline Macaé-Rio das Ostras & 13.591 & 3,6 & 82.428 & 18,9 & 19.172 & 4,4 & 63.256 & 16,5 & 2,9 \\
\hline Mendes - Engenheiro Paulo de Frontin & 503 & 1,6 & 2.465 & 0,6 & 2.935 & 0,7 & -470 & $-1,5$ & 0,9 \\
\hline Paty do Alferes - Miguel Pereira & 1.028 & 2,0 & 4.684 & 1,1 & 3.766 & 0,9 & 918 & 1,8 & 1,2 \\
\hline Petrópolis & 994 & 0,3 & 11.362 & 2,6 & 17.737 & 4,1 & -6.375 & $-2,1$ & 0,7 \\
\hline Resende & 4.409 & 2,5 & 9.661 & 2,2 & 5.869 & 1,3 & 3.792 & 2,1 & 1,4 \\
\hline Rio de Janeiro & 523.183 & 4,4 & 90.760 & 20,8 & 203.270 & 46,6 & -112.510 & $-0,9$ & 0,8 \\
\hline Santo Antônio de Pádua & 127 & 0,3 & 3.721 & 0,9 & 3.129 & 0,7 & 592 & 1,2 & 1,2 \\
\hline Três Rios - Paraíba & 2.158 & 1,7 & 6.171 & 1,4 & 5.427 & 1,2 & 744 & 0,6 & 1,1 \\
\hline Valença $^{3}$ & 0 & 0,0 & 4.668 & 1,1 & 4.967 & 1,1 & -299 & $-0,4$ & 0,9 \\
\hline Barra Mansa - Volta Redonda & 8.970 & 2,0 & 15.687 & 3,6 & 22.585 & 5,2 & -6.898 & $-1,5$ & 0,8 \\
\hline Municípios isolados & 28.150 & 0,2 & 85.116 & 19,5 & 78.291 & 17,9 & 6.825 & 0,0 & 1,1 \\
\hline Total & 600.269 & & 436.339 & 100,0 & 436.339 & 100,0 & 0 & - & - \\
\hline
\end{tabular}

Fonte: IBGE - censos demográficos de 2000 e 2010.

1) Este aglomerado urbano é formado pelos municípios de Além Paraíba (MG) e Sapucaia (RJ). Nesta Tabela as informações se restringem ao município pertencente ao estado fluminense.

2) Aglomerado constituído pelos municípios de Bom Jesus do Itabapoana (RJ) e Bom Jesus do Norte (ES). Nesta Tabela as informações se restringem ao município pertencente ao estado fluminense.

3) Aglomerado constituído pelos municípios de Valença (RJ) e Rio Preto (MG). Nesta Tabela as informações se restringem ao município pertencente ao estado fluminense. 
Como se pode notar, entre 2000 e 2010, as migrações internas no estado do Rio de Janeiro envolveram um total de 1.036 .608 indivíduos; contra 823.769 migrantes no decênio 1981-1991 (ibid.). Na segunda coluna da Tabela 4, apresentam-se os fluxos migratórios intra-aglomerados, ou seja, entre municípios de um mesmo aglomerado urbano. Como se trata de aglomerados com volumes populacionais distintos, o significado desses fluxos em cada contexto específico é mais bem analisado pelo quociente entre o número total de migrantes e a população residente (terceira coluna). Tomando-se como referência a migração intrametropolitana - que é, reconhecidamente, a maior fomentadora do processo de periferização metropolitana e que, entre 2000 e 2010, envolveu um total de 523.183 indivíduos, ou seja, $4,4 \%$ da população total residente - são também expressivas as migrações "intra" nos aglomerados Macaé-Rio das Ostras (3,6\%), Cabo Frio (3,4\%), Cordeiro-Cantagalo (3,1\%) e Resende (2,5\%). Esses movimentos, apesar de não alterarem as taxas de crescimento populacional dos aglomerados, redistribuem a população entre seus municípios, refletindo mecanismos internos de seletividade, e alteram as taxas de crescimento populacional dos municípios, individualmente.

No contexto das migrações intraestaduais, exclusive intra-aglomerados, o Rio de Janeiro, que atrai 20,8\% dos imigrantes, por um lado, não se isola como área de atração populacional, dividindo esse papel com Macaé $(18,9 \%)$ e Cabo Frio (14,8\%). Mas, por outro lado, tendo sido identificado como a origem de $46,6 \%$ dos migrantes, isola-se como área de emigração. 0 aglomerado metropolitano Rio de
Janeiro é o que exibe o maior saldo negativo (-112.510 migrantes), seguido por Campos dos Goytacazes (-12.551), no Norte fluminense, enquanto os saldos positivos mais elevados foram verificados em Macaé-Rio das Ostras, Cabo Frio e Araruama, aglomerados cujos crescimentos populacionais apresentaram-se fortemente influenciados pelos movimentos migratórios, o que se pode constatar através das elevadas Taxas Líquidas de Migração (TLM).

Como o Rio de Janeiro é o aglomerado de mais expressivo saldo negativo, ele revela-se, sem dúvida, o maior fomentador do processo de interiorização. Nesse sentido, torna-se imprescindível analisar tanto as origens de seus imigrantes quanto o destino de seus emigrantes, pois, por meio dessas variáveis, compreenderemos a interação deste com os demais aglomerados.

Observa-se na Tabela 5, que o aglomerado metropolitano apresenta saldo migratório negativo, com a maioria dos aglomerados urbanos não metropolitanos, sendo Cordeiro-Cantagalo, Petrópolis e Barra Mansa-Volta Redonda, as únicas exceções. As trocas líquidas positivas com esses aglomerados são, em geral, inexpressivas. Como principais áreas de origens dos imigrantes daquele aglomerado, identificam-se, além dos "municípios isolados" (tradicional migração interior-capital), os aglomerados Petrópolis, Cabo Frio, Campos dos Goytacazes e Macaé-Rio das Ostras. Os municípios isolados destacam-se também como principais destinos, absorvendo $24,5 \%$ dos emigrantes do Rio de Janeiro, sugerindo haver forte migração de retorno para o interior (não necessariamente para o mesmo município isolado de origem). Além daqueles, destacam-se como 
principais destinos, os aglomerados Cabo Frio, Macaé-Rio das Ostras e Araruama - que absorveram, em conjunto, praticamente $56 \%$ dos emigrantes. Exatamente com esses aglomerados é que o Rio de Janeiro apresentou seus maiores saldos negativos.

\section{Tabela 5 - Aglomerado metropolitano Rio de Janeiro - Migração intraestadual}

\begin{tabular}{|c|c|c|c|c|c|}
\hline \multirow{2}{*}{ Aglomerado Urbano } & \multicolumn{5}{|c|}{ Migração intraestadual - Aglomerado Rio de Janeiro } \\
\hline & 1 & $\%$ & $\mathbf{E}$ & $\%$ & Saldo \\
\hline Além Paraíba - Sapucaia ${ }^{1}$ & 219 & 0,2 & 275 & 0,1 & -56 \\
\hline Araruama & 4.406 & 4,9 & 22.052 & 10,8 & -17.646 \\
\hline Bom Jesus do Itabapoana² & 664 & 0,7 & 955 & 0,5 & -291 \\
\hline Cabo Frio & 8.712 & 9,6 & 46.483 & 22,9 & -37.771 \\
\hline Campos dos Goytacazes & 8.259 & 9,1 & 9.090 & 4,5 & -831 \\
\hline Cordeiro-Cantagalo & 978 & 1,1 & 892 & 0,4 & 86 \\
\hline Itaocara & 416 & 0,5 & 1.443 & 0,7 & -1.027 \\
\hline Macaé-Rio das Ostras & 8.210 & 9,0 & 45.069 & 22,2 & -36.859 \\
\hline Mendes - Engenheiro Paulo de Frontin & 1.261 & 1,4 & 1.325 & 0,7 & -64 \\
\hline Paty do Alferes - Miguel Pereira & 1.942 & 2,1 & 3.208 & 1,6 & -1.266 \\
\hline Petrópolis & 9.798 & 10,8 & 7.399 & 3,6 & 2.399 \\
\hline Resende & 2.774 & 3,1 & 3.939 & 1,9 & -1.165 \\
\hline Santo Antônio de Pádua & 1.079 & 1,2 & 1.443 & 0,7 & -364 \\
\hline Três Rios - Paraíba & 1.958 & 2,2 & 2.508 & 1,2 & -550 \\
\hline Valença ${ }^{3}$ & 1.314 & 1,4 & 1.800 & 0,9 & -486 \\
\hline Barra Mansa - Volta Redonda & 6.085 & 6,7 & 5.566 & 2,7 & 519 \\
\hline Municípios isolados & 32.685 & 36,0 & 49.823 & 24,5 & -17.138 \\
\hline Total & 90.760 & 100,0 & 203.270 & 100,0 & -112.510 \\
\hline
\end{tabular}

Fonte: IBGE - censos demográficos de 2000 e 2010.

1. Este aglomerado urbano é formado pelos municípios de Além Paraíba (MG) e Sapucaia (RJ). Nesta Tabela as informações se restringem ao município pertencente ao estado fluminense.

2. Aglomerado constituído pelos municípios de Bom Jesus do Itabapoana (RJ) e Bom Jesus do Norte (ES). Nesta Tabela as informações se restringem ao município pertencente ao estado fluminense.

3. Aglomerado constituído pelos municípios de Valença (RJ) e Rio Preto (MG). Nesta Tabela as informações se restringem ao município pertencente ao estado fluminense. 


\section{Aglomerados do Litoral Norte: processo incipiente de metropolização?}

Os aglomerados urbanos do Litoral Norte não chamam a nossa atenção apenas porque apresentam elevadas taxas de crescimento e por constituírem, na atualidade, a principal frente de interiorização do estado. Outro motivo que nos leva a centrar nossas atenções em tais aglomerados é a possibilidade de que se tornem, num futuro próximo, uma região metropolitana. A questão é compreender se essa possível região metropolitana resultará de um processo ou apenas de um decreto estadual, ainda que a interação entre seus municípios não tenha características metropolitanas.

Para se analisar se há ou não um processo de metropolização em curso, será verificada, nesta seção, a existência (ou não) de um dinamismo demográfico entre os municípios dos distintos arranjos. Para tanto, serão considerados os volumes populacionais, as densidades demográficas e os movimentos migratórios e pendulares, como sugere a literatura exposta na segunda seção deste artigo.

A população total desses aglomerados, que era de 885.466 habitantes, em 2000, aumentou para 1.208.176, em 2010: uma variação absoluta de 322.710 habitantes, a um ritmo médio anual de 3,2\%, uma taxa de crescimento significativamente maior do que a média estadual, de 1,06\% ao ano, como dito anteriormente.

Nota-se, na Tabela 6, ter havido, entre 2000 e 2010, uma considerável redistribuição espacial dessa população, entre municípios dos três aglomerados especiais: apesar de a população permanecer concentrada na cidade-polo do aglomerado Campos dos Goytacazes, esta se reduziu de $49,1 \%$ para $41,1 \%$. Além disso, a população residente em Macaé-Rio das Ostras, que em 2000 correspondia a 24,1\% da população do conjunto dos aglomerados especiais, aumentou sua participação relativa para 31,6\%, em 2010. Basicamente, isso aconteceu em decorrência do crescimento populacional dos dois municípios que dão nome ao aglomerado, principalmente o último.

0 aglomerado de Campos dos Goytacazes, apesar de ser o maior em volume populacional, é o de menor densidade demográfica, dado que ocupa vasta extensão territorial (Campos é o maior município em extensão territorial do estado do Rio de Janeiro). Sua taxa de crescimento populacional, de 1,33\% ao ano, foi a menor, comparativamente aos demais aglomerados, assim como sua participação relativa no incremento populacional absoluto do conjunto dos aglomerados especiais.

Nos outros aglomerados, o crescimento populacional se deu a um ritmo bastante acelerado: 5,8\% em Macaé-Rio das Ostras e 3,6\% em Cabo Frio. No primeiro, apenas Conceição de Macabu apresentou crescimento mais lento, chamando a atenção o extraordinário ritmo de crescimento e a densidade demográfica de Rio das Ostras.

No segundo, a única exceção é Arraial do Cabo, com uma taxa de crescimento de 1,5\% ao ano. Nesse caso, como se mencionou, o acelerado crescimento relaciona-se às atividades ligadas ao setor de turismo e às atividades da indústria petrolífera.

0 crescimento populacional de Macaé-Rio das Ostras foi o maior responsável - 50,8\% - pelo incremento populacional 
Tabela 6 - Aglomerados urbanos especiais -

População, densidade demográfica, taxa de crescimento médio anual, participação relativa no incremento absoluto (2000-2010)

\begin{tabular}{|c|c|c|c|c|c|c|c|c|c|}
\hline \multirow{2}{*}{$\begin{array}{c}\text { Municípios/ } \\
\text { Arranjos Populacionais }\end{array}$} & \multicolumn{5}{|c|}{ População } & \multirow{2}{*}{$\begin{array}{c}\text { Densidade } \\
\text { Demográfica } \\
(\text { hab/Km²) }\end{array}$} & \multirow{2}{*}{$\begin{array}{c}\Delta \\
\text { Populacional } \\
\text { absoluta }\end{array}$} & \multirow{2}{*}{$\begin{array}{c}\text { Taxa de } \\
\text { crescimento } \\
\text { médio anual } \\
(2000-2010)\end{array}$} & \multirow{2}{*}{$\begin{array}{c}\text { Participação } \\
\text { relativa no } \\
\text { incremento } \\
\text { absoluto }\end{array}$} \\
\hline & 2000 & $\%$ & 2010 & $\%$ & $\begin{array}{l}\text { Área } \\
\left(\mathrm{Km}^{2}\right)\end{array}$ & & & & \\
\hline Armação dos Búzios & 18.204 & 2,1 & 27.560 & 2,3 & 70,3 & 392,2 & 9.356 & 4,2 & 2,9 \\
\hline Arraial do Cabo & 23.877 & 2,7 & 27.715 & 2,3 & 160,3 & 172,9 & 3.838 & 1,5 & 1,2 \\
\hline Cabo Frio & 126.828 & 14,3 & 186.227 & 15,4 & 410,4 & 453,7 & 59.399 & 3,9 & 18,4 \\
\hline São Pedro da Aldeia & 63.227 & 7,1 & 87.875 & 7,3 & 332,8 & 264,1 & 24.648 & 3,3 & 7,6 \\
\hline CABO FRIO & 232.136 & 26,2 & 329.377 & 27,3 & 973,8 & 338,2 & 97.241 & 3,6 & 30,1 \\
\hline Campos dos Goytacazes & 407.168 & 46,0 & 463.731 & 38,4 & 4026,7 & 115,2 & 56.563 & 1,3 & 17,5 \\
\hline São João da Barra & 27.682 & 3,1 & 32.747 & 2,7 & 455,0 & 72,0 & 5.065 & 1,7 & 1,6 \\
\hline CAMPOS & 434.850 & 49,1 & 496.478 & 41,1 & 4481,7 & 110,8 & 61.628 & 1,3 & 19,1 \\
\hline Carapebus & 8.666 & 1,0 & 13.359 & 1,1 & 308,1 & 43,4 & 4.693 & 4,4 & 1,5 \\
\hline Casimiro de Abreu & 22.152 & 2,5 & 35.347 & 2,9 & 460,8 & 76,7 & 26.681 & 4,8 & 4,1 \\
\hline Conceição de Macabu & 18.782 & 2,1 & 21.211 & 1,8 & 347,3 & 61,1 & -941 & 1,2 & 0,8 \\
\hline Macaé & 132.461 & 15,0 & 206.728 & 17,1 & 1216,8 & 169,9 & 74.267 & 4,6 & 23,0 \\
\hline Rio das Ostras & 36.419 & 4,1 & 105.676 & 8,7 & 229,0 & 461,4 & 69.257 & 11,2 & 21,5 \\
\hline MACAÉ & 218.480 & 24,7 & 382.321 & 31,6 & 2562,1 & 149,2 & 163.841 & 5,8 & 50,8 \\
\hline Total & 885.466 & 100,0 & 1.208 .176 & 100,0 & 8.018 & 150,7 & 322.710 & 3,2 & 100,0 \\
\hline
\end{tabular}

Fonte: IBGE - censos demográficos de 2000 e 2010.

absoluto dos aglomerados especiais, seguido por Cabo Frio (30,1\%).

Observa-se, na Tabela 7, que, apesar de a maior interação, do ponto de vista tanto da imigração, quanto da emigração, ser mais intensa com "outros aglomerados urbanos" (aglomerados urbanos do Rio de Janeiro, exclusive aglomerados especiais), não se pode negar a grande interação entre municípios de um mesmo aglomerado especial: a migração intra-aglomerados representou, em Cabo Frio, 14,7\% da imigração e 37,0\% da emigração total; em Campos dos Goytacazes, $16,7 \%$ da imigração e $10,5 \%$ da emigração total; e em Macaé-Rio das Ostras, 14,2\% e $41,5 \%$, respectivamente.

As trocas populacionais entre os aglomerados especiais - que totalizam 25.845 indivíduos - também não podem ser desprezadas: representam 9,7\% da imigração e 37\% da emigração total de Cabo Frio; $18,2 \%$ da imigração e $10,5 \%$ da emigração total de Campos dos Goytacazes; e 15,22\% e 16,3\% da emigração total de Macaé-Rio das Ostras. 
Tabela 7 - Aglomerados especiais - Migrações internas (2000-2010)

\begin{tabular}{l|r|r|r|r|r|r|r}
\hline \multirow{2}{*}{$\begin{array}{l}\text { Aglomerados } \\
\text { especiais }\end{array}$} & \multirow{2}{*}{\begin{tabular}{l} 
Intra \\
\cline { 3 - 8 }
\end{tabular}} & & \multicolumn{3}{|c|}{ Imigrantes } & \multicolumn{3}{c}{ Emigrantes } \\
\cline { 3 - 8 } & & $\mathrm{I}_{\text {Agl.Especiais }}$ & $\mathrm{I}_{\text {outros Agl. }}$ & \multicolumn{1}{c|}{$\mathrm{I}_{\text {Total }}$} & $\mathrm{E}_{\text {Agl.Especiais }}$ & $\mathrm{E}_{\text {outros Agl. }}$ & $\mathrm{E}_{\text {Total }}$ \\
\hline Cabo Frio & 11.060 & 7.297 & 57.073 & 75.430 & 4.828 & 14.035 & 29.923 \\
Campos dos Goytacazes & 3.599 & 3.931 & 14.085 & 21.615 & 15.682 & 14.885 & 34.166 \\
Macaé & 13.591 & 14.617 & 67.811 & 96.019 & 5.335 & 13.837 & 32.763 \\
\hline Total & 28.250 & 25.845 & 138.969 & 193.064 & 25.845 & 42.757 & 96.852 \\
\hline
\end{tabular}

\begin{tabular}{l|c|c|c|c|c|c|c|c}
\hline \multicolumn{1}{c|}{$\begin{array}{c}\text { Aglomerados } \\
\text { especiais }\end{array}$} & $\mathrm{I}_{\text {Intra }}$ & $\mathrm{I}_{\text {Agl.Especiais }}$ & $\mathrm{I}_{\text {outros Agl. }}$ & $\mathrm{I}_{\text {Total }}$ & $\mathrm{E}_{\text {Intra }}$ & $\mathrm{E}_{\text {Agl.Especiais }}$ & $\mathrm{E}_{\text {outros Agl. }}$ & $\mathrm{E}_{\text {Total }}$ \\
\hline Cabo Frio & 14,7 & 9,7 & 75,7 & 100,0 & 37,0 & 16,1 & 46,9 & 100,0 \\
Campos dos Goytacazes & 16,7 & 18,2 & 65,2 & 100,0 & 10,5 & 45,9 & 43,6 & 100,0 \\
Macaé & 14,2 & 15,2 & 70,6 & 100,0 & 41,5 & 16,3 & 42,2 & 100,0 \\
\hline Total & 14,6 & 13,4 & 72,0 & 100,0 & 29,2 & 26,7 & 44,1 & 100,0 \\
\hline
\end{tabular}

Fonte: IBGE - censos demográficos de 2000 e 2010.

Na Matriz Origem Destino (Matriz 0-D 1), podem-se observar os fluxos migratórios entre os aglomerados especiais. Nas linhas, temos as imigrações e, nas colunas, as emigrações.

A Tabela 8 traz os resultados sumarizados da Matriz O-D. Observa-se que, no contexto dos aglomerados especiais, Macaé-Rio das Ostras se isola como área de atração, absorvendo $56,6 \%$ dos imigrantes. Isso se explica principalmente (a) pela concentração da atividade petrolífera e parapetrolífera naquele aglomerado e consequente demanda por mão de obra; e (b) pela dinâmica do mercado imobiliário, cujos preços praticados em alguns municípios são ainda relativamente baixos comparativamente àqueles praticados em municípios de outros aglomerados. Além disso, Campos dos Goytacazes se isola como área de emigração, constituindo, portanto, um importante reservatório de força de trabalho, mais notadamente para Macaé-Rio das Ostras.

Em termos líquidos, Cabo Frio e Macaé apresentam saldos migratórios positivos, enquanto Campos dos Goytacazes apresenta saldo migratório negativo elevado. 
Matriz O-D 1 - Aglomerados Especiais Migração de última etapa (2000-2010)

\begin{tabular}{|c|c|c|c|c|c|}
\hline & & \multicolumn{4}{|c|}{ Aglomerado onde se localiza o município de trabalho } \\
\hline & & Cabo Frio & $\begin{array}{c}\text { Campos dos } \\
\text { Goytacazes }\end{array}$ & $\begin{array}{l}\text { Macaé- } \\
\text { Rio das Ostras }\end{array}$ & Total \\
\hline \multirow{4}{*}{ 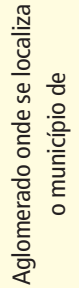 } & Cabo Frio & & 4.641 & 2.656 & 7.297 \\
\hline & Campos dos Goytacazes & 1.252 & & 2.679 & 3.931 \\
\hline & Macaé-Rio das Ostras & 3.576 & 11.041 & & 14.617 \\
\hline & Total & 4.828 & 15.682 & 5.335 & 25.845 \\
\hline
\end{tabular}

Fonte: IBGE - censos demográficos de 2000 e 2010.

Tabela 8 - Aglomerados Especiais Indicadores da migração de última etapa (2000-2010)

\begin{tabular}{l|c|c|c|c|c}
\hline \multicolumn{1}{c|}{ Aglomerados especiais } & I & $\%$ & E & $\%$ & Saldo \\
\hline Cabo Frio & 7.297 & 28,2 & 4.828 & 18,7 & 2.469 \\
Campos dos Goytacazes & 3.931 & 15,2 & 15.682 & 60,7 & -11.751 \\
Macaé-Rio das Ostras & 14.617 & 56,6 & 5.335 & 20,6 & 9.282 \\
\hline Total & 25.845 & 100,0 & 25.845 & 100,0 & 0 \\
\hline
\end{tabular}

Fonte: IBGE - censos demográficos de 2000 e 2010. 
Como se mencionou na primeira seção, outro indicador que deve ser levado em consideração para se analisar a integração entre municípios é a pendularidade. 0 Censo Demográfico de 2010 permite-nos estimar a pendularidade - por trabalho e estudo - em sentido amplo e estrito (Souza, Terra e Campos, 2015). Neste artigo, que tem como objetivo analisar as relações de dependência entre os municípios dos aglomerados especiais, optou-se por considerar a pendularidade em seu sentido mais amplo, no qual é considerado pendular todo indivíduo cujo município de residência difere do município onde se localiza a instituição de trabalho ou se estudo, independentemente do retorno diário do indivíduo para casa (pendularidade estrita).

É oportuno elucidar que trabalho e estudo são os únicos motivos de pendularidade considerados nos censos demográficos brasileiros, ressaltando-se que eles são, de fato, seus principais determinantes. No entanto, é interessante notar que os fluxos pendulares são, na realidade, maiores do que os resultados aqui apresentados, dado que há outros motivos que levam a esses movimentos, tais como saúde (consultas médicas), lazer e consumo, por exemplo.

Considerando-se o motivo trabalho, são enormes os fluxos pendulares entre municípios de um mesmo aglomerado e entre os aglomerados (Tabela 9). 0 aglomerado Macaé-Rio das Ostras chama a atenção: a) devido à elevada pendularidade interna: um fluxo interno de 21.272 trabalhadores, sendo, desse total, 17.784 (83,6\%), indivíduos residentes em Carapebus, Casimiro de Abreu, Conceição de Macabu e, principalmente, Rio das Ostras, e que trabalham em Macaé. Essa pendularidade é, na verdade, estrita, uma vez que, dada a proximidade espacial, os indivíduos retornam para casa diariamente; b) por apresentar saldo pendular positivo, recebendo mais do que enviando trabalhadores para Campos e Cabo Frio.

No contexto do trabalho, o município de Macaé destaca-se como centralidade, por ser o que mais absorve a mão de obra pendular - tendo recebido $28.164(57,8 \%)$ do total

Tabela 9 - Aglomerados Especiais -

Indicadores de movimentos pendulares por motivo trabalho "intra" e "inter" aglomerados

\begin{tabular}{|c|c|c|c|c|}
\hline \multirow{2}{*}{ Aglomerados especiais } & \multirow{2}{*}{$\begin{array}{c}\text { Intra- } \\
\text {-aglomerado }\end{array}$} & \multicolumn{3}{|c|}{ Inter-aglomerados } \\
\hline & & Entrada & Saídas & Saldo \\
\hline Cabo Frio & 9.413 & 1.040 & 6.413 & -5.373 \\
\hline Campos dos Goytacazes & 2.604 & 1.257 & 7.271 & -6.014 \\
\hline Macaé-Rio das Ostras & 21.272 & 13.162 & 1.775 & 11.387 \\
\hline Total & 33.289 & 15.459 & 15.459 & 0 \\
\hline
\end{tabular}

Fonte: IBGE - censos demográficos de 2000 e 2010. 
de trabalhadores pendulares, notadamente dos municípios de Rio das Ostras e Campos dos Goytacazes -; e também por ser o de maior retenção e o de menor expulsão de sua força de trabalho - o Censo de 2010 indica uma saída de 1.010 trabalhadores daquele município (apenas $2 \%$ do total de trabalhadores pendulares).

Souza e Terra (2015) elaboraram um indicador de Dependência de mão de obra exógena, utilizando como estudos de caso dez municípios produtores de petróleo da Bacia de Campos. As autoras observaram

[...] apenas em Armação dos Búzios e em Macaé, a PEA ocupada no município é, de fato, superior à residente. Isso significa que, mesmo se toda a população ocupada residente nesses municípios fosse completamente absorvida pelos respectivos mercados de trabalho, ainda assim faltariam trabalhadores para ocuparem todos os postos de trabalho existentes. Em Armação de Búzios, a população ocupada é $48,31 \%$ maior que a ocupada residente; já em Macaé esse percentual é de 47,99\%. Provavelmente, no período censitário, havia indivíduos residentes desempregados nesses municípios, o que não é um paradoxo [...]. Como se observa, o nível de dependência ampliado é relativamente alto em todos os municípios [...]. Armação de Búzios e Macaé apresentaram um índice superior a 50\%, mostrando, assim, um nível extremamente alto de dependência de mão de obra exógena: $55,38 \% 59,69 \%$, respectivamente [...]. Já em relação ao indicador mais estrito, que restringe o numerador aos movimentos pendulares, Búzios e Macaé permanecem com os índices mais elevados: $35,34 \%$ e $34,18 \%$, nessa ordem. (ibid., pp. 138-139)

Os fluxos pendulares por motivo estudo são significativamente menores, mas ainda assim indicam forte integração entre municípios de um mesmo aglomerado e dos aglomerados especiais ${ }^{4}$ (Tabela 10).

No contexto do estudo, Cabo Frio continua apresentando saldo negativo, mas Campos dos Goytacazes passa a exibir saldo positivo, ainda que pequeno, fato que surpreende, tendo em vista a concentração de grandes e importantes instituições de ensino - UENF, UFF, IFF - no município-polo. Mais uma vez, Macaé destaca-se pelo saldo positivo relativamente elevado, mas, nesse caso, não ocupa papel de centralidade.

Tabela 10 - Aglomerados Especiais Indicadores de movimentos pendulares por motivo estudo "intra" e "inter" aglomerados

\begin{tabular}{|c|c|c|c|c|}
\hline \multirow{2}{*}{ Aglomerados especiais } & \multirow{2}{*}{$\begin{array}{c}\text { Intra- } \\
\text {-aglomerado }\end{array}$} & \multicolumn{3}{|c|}{ Inter-aglomerados } \\
\hline & & Entrada & Saídas & Saldo \\
\hline Cabo Frio & 7.659 & 419 & 2.684 & -2.265 \\
\hline Campos dos Goytacazes & 1.444 & 1.211 & 293 & 918 \\
\hline Macaé-Rio das Ostras & 5.295 & 2.729 & 1.382 & 1.347 \\
\hline Total & 14.398 & 4.359 & 4.359 & 0 \\
\hline
\end{tabular}

Fonte: IBGE - censos demográficos de 2000 e 2010. 


\section{Considerações finais}

No estado do Rio de Janeiro, a população permanece extremamente concentrada na RMRJ, mais notadamente na própria capital. No entanto, paralelamente aos processos de metropolização e periferização, está em curso um processo incipiente de interiorização do crescimento, cujo principal vetor de expansão, pelo menos a partir dos anos 1980, tem sido o Litoral Norte fluminense. A formação desse vetor relaciona-se ao extravasamento da RMRJ para áreas interioranas contíguas, como Saquarema e Araruama; ao desenvolvimento do setor de turismo, como é o caso de Cabo Frio e Armação dos Búzios; e, principalmente ao desenvolvimento da indústria petrolífera e parapetrolífera, nos aglomerados de Cabo Frio, Macaé-Rio da Ostras e Campos dos Goytacazes.

Em relação ao objetivo principal do artigo, que é analisar se há ou não um processo de metropolização em curso, envolvendo os três aglomerados, as informações referentes às migrações e aos movimentos pendulares inter-aglomerados confirmam a existência de uma grande interação demográfica entre municípios de aglomerados distintos, o que leva a admitir a incipiência de um processo de metropolização em toda essa extensão territorial. Nesse caso, o município de Macaé, sede de operações das diversas indústrias petrolíferas que atuam na Bacia de Campos, desponta como centralidade, papel até então ocupado por Campos dos Goytacazes.

No entanto, é preciso considerar que essas inferências foram tomadas a partir dos dados dos Censos de 2000 e 2010, e que, recentemente, mais precisamente a partir de 2015, muitas características até então identificadas podem ter sofrido alterações devido à queda do preço do barril de petróleo no mercado internacional; crise institucional da Petrobras e de algumas outras empresas do setor petrolífero e da construção civil, em decorrência da Operação Lava Jato e da atual crise econômica e política brasileira. Lamentavelmente, é impossível, neste momento, analisar o impacto desses eventos sobre a dinâmica demográfica que envolve os três aglomerados, mais precisamente sobre o processo incipiente de metropolização que foi identificado em curso. Isso só será possível com os dados do próximo censo demográfico.

\footnotetext{
Joseane de Souza

Universidade Estadual do Norte Fluminense Darcy Ribeiro, Centro de Ciências do Homem, laboratório de Gestão e Políticas Públicas. Graduação em Administração Pública e Ciências Sociais. Programa de Pós-Graduação em Sociologia Política e Políticas Sociais. Campos dos Goytacazes, RJ/Brasil.

joseanedesouza.souza@gmail.com

\section{Denise Cunha Tavares Terra}

Universidade Estadual do Norte Fluminense Darcy Ribeiro, Centro de Ciências do Homem, Laboratório de Gestão e Políticas Públicas. Graduação em Administração Pública. Programa de Pós-Graduação em Políticas Sociais. Campos dos Goytacazes, RJ/Brasil.

deniseterra@gmail.com
} 


\section{Notas}

1) Para maior detalhamento, consulte a publicação original do IBGE (Brasil//BGE, 2015).

2) Para ambos os períodos, foram consideradas as formações de 2010, definidas pelo IBGE (Brasil/ IBGE, 2015).

3) Esse aglomerado urbano é formado por 21 municípios, a saber: Belford Roxo, Duque de Caxias, Guapimirim, Itaboraí, Itaguaí, Queimados, Rio de Janeiro, São Gonçalo, São João de Meriti, Seropédica, Tanguá, Japeri, Magé, Mangaratiba, Maricá, Mesquita, Nilópolis, Niterói, Nova Iguaçu, Saquarema e Paracambi. Sua diferença em relação à RMRJ é que dois de seus municípios - Cachoeira de Macacu e Rio Bonito - não fazem parte desse aglomerado. Ao passo que Mangaratiba e Saquarema, que fazem parte do aglomerado metropolitano, não fazem parte da RMRJ. Neste artigo, estamos analisando os dados do aglomerado, os quais, indubitavelmente, são representativos da RMRJ.

4) As matrizes de pendularidade por motivo trabalho e estudo não podem ser diretamente somadas, devido à dupla contagem daqueles que trabalham e estudam em um mesmo município diferente do município de residência. Para que sejam somadas, é preciso excluir, da matriz de estudo, os indivíduos que trabalham. Nesse caso, como o objetivo é analisar a integração, consideramos todos os que estudam em município diferente do de residência, incluindo os pendulares por motivo trabalho.

\section{Referências}

AZEVEDO, S. e LOBO, Y. (2015). "O processo de fusão e o novo Estado do Rio de janeiro: a questão institucional". In: RIBEIRO, L. C. Q. (org.). Rio de Janeiro: transformações na ordem urbana. (Coleção Metrópoles: Território, coesão social e governança democrática). Rio de Janeiro, Letra Capital. Observatório das Metrópoles, pp. 45-78.

BAENINGER, R. (2001). "Região Metropolitana de Campinas: expansão e consolidação do urbano paulista”. In: HOGAN, D. J.; CUNHA, J. M. P. da; BAENINGER, R. A. e CARMO, R. L. do (orgs.). Migração e Ambiente nas Aglomerações Urbanas. Campinas, MPC Artes Gráficas em Papel.

BAENINGER, R. e GONÇALVES, R. (2000). Novas espacialidades no processo de urbanização: a Região Metropolitana de Campinas. In: ENCONTRO NACIONAL DE ESTUDOS POPULACIONAIS, 12. Caxambu-MG. Anais. Campinas, Abep.

BARRETO, I. J. (2012). Espaço e economia. Revista Brasileira de Geografia Econômica, Ano I, n. 1. O surgimento de novas regiões metropolitanas no Brasil: uma discussão a respeito do caso de Sorocaba (SP). Disponível em: http://espacoeconomia.revues.org/374. Acesso em: 25 mar 2017.

BRAGA, R. e CARVALHO, P. F. de (2004). Cidade: espaço de cidadania. III ENCONTRO NACIONAL DA REDE BRASILEIRA DE CIDADES MÉDIAS. Anais. Disponível em: http://www.redbcm.com.br/ arquivos/bibliografia/cidade\%20espa\%C3\%A7o\%20da\%20cidadania\%20rbraga11.pdf. Acesso em: 25 mar 2017 
BRASIL (1967). Constituição Federal. Disponível em: http://www.planalto.gov.br/ccivil_03/ constituicao/constituicao67.htm. Acesso em: 25 mar 2017.

(1969). Emenda Constitucional. Disponível em http://www.planalto.gov.br/ccivil_03/ Constituicao/Emendas/Emc_anterior1988/emc01-69.htm. Acesso em: 25 mar 2017.

(1988).ConstituiçãoFederal.Disponível em: http://www.planalto.gov.br/ccivil_03/constituicao/ constituicao.htm. Acesso em: 25 mar 2017.

BRASIL/IBGE (2015). Arranjos populacionais e concentrações urbanas do Brasil. Rio de Janeiro.

BRITO, F.; HORTA, C. J. G. e AMARAL, E. (2001). A urbanização recente no Brasil e as aglomerações metropolitanas. Cedeplar - IUSSP. Disponível em: http://www.scielo.br/scielo.php?script=sci_ nlinks\&ref=000114\&pid=S0102-8839200500040000300001\&lng=en. Acesso em: 25 mar 2017.

CANO, W. (1989). Urbanização: sua crise e revisão de seu planejamento. Revista de Economia Política, v. 9.

CARLOS, A. F. (2009). A metrópole de São Paulo no contexto da urbanização contemporânea. Estudos Avançados, v. 23, n. 66.

CARMO, S. de C. B. do (2004). Câmara e Agenda 21 Regional para uma rede de cidades sustentáveis: A Região Metropolitana da Baixada Santista. Dissertação de Mestrado. São Carlos, Universidade Federal de São Carlos.

CASTELLS, M. (2000). A questão urbana. Coleção Pensamento Crítico. Rio de Janeiro, Paz e Terra.

COSTA, M. A. (2013). "Quarenta anos de Regiões Metropolitanas no Brasil: um breve balanço exploratório". In: COSTA, M. A. e TSUKUMO, I. T. L. (orgs.). 40 anos de regiões metropolitanas no Brasil. Brasília, Ipea.

DAVIDOVICH, F. (2001). Metrópole e território: metropolização do espaço no Rio de Janeiro. Cadernos Metrópole. São Paulo, n. 6, pp. 67-77.

FIRKOWISKI, O. L. C. de F. (2012). Por que as Regiões Metropolitanas no Brasil são Regiões mas não são Metropolitanas. Revista Paranaense de Desenvolvimento. Curitiba, n. 122, pp. 19-38.

FREITAS, R. (2009). Regiões Metropolitanas: uma abordagem conceitual. Humanae, v. 1, pp. 44-53.

HOTZ, E. F. (2000). Organização Metropolitana Pós Constituição de 1988. São Paulo em Perspectiva, v. 14, n. 4.

IBGE - INSTITUTO BRASILEIRO DE GEOGRAFIA E ESTATÍ́STICA (2000). Censo demográfico. (2010). Censo demográfico.

(2017). Censo demográfico. Disponível em: ww2.ibge.gov.br/home/geociências. Acesso em: 5 mar 2017.

MINAS GERAIS (1990). Constituição Estadual. Disponível em: https://www.almg.gov.br/export/sites/ default/consulte/legislacao/Downloads/pdfs/ConstituicaoEstadual.pdf. Acesso em: 26 mar 2017.

MOTTA, D. M. da e AJARA, C. (2001). Configuração da Rede Urbana do Brasil. Revista Paranaense de Desenvolvimento. Curitiba, n. 100, pp. 7-25.

MOURA, R.; LIBARDI, D. e BARION, M. I. (2006). Institucionalização de Regiões Metropolitanas: qual o sentido? Revista Paranaense de Desenvolvimento. Curitiba, n. 111, pp. 129-143.

SANTOS, M. (2005). A urbanização brasileira. São Paulo, Edusp. 
SÃO PAULO (1989). Constituição Estadual. Disponível em: http://www.legislacao.sp.gov.br/legislacao/ dg280202.nsf/a2dc3f553380ee0f83256cfb00501463/46e2576658b1c52903256d63004f305a?O penDocument. Acesso em: 26 mar 2017.

SOUZA, J. e FRUTUOZO, J. V. de P. (no prelo). Rio de Janeiro: considerações sobre os processos de expansão urbana e interiorização do crescimento (1980-2010).

SOUZA, J.; TERRA, D. C. T. e CAMPOS, M. (2015). Mobilidade populacional e as novas espacialidades urbanas: municípios da Ompetro, Rio de Janeiro (2000-2010). Eure. Santiago, v. 41, n. 123 , pp. 53-80. Disponível em: http://www.scielo.cl/pdf/eure/v41n123/art03.pdf. Acesso em: 14 abr 2017.

SOUZA, J. e TERRA, D. C. T. (2015). Indústria petrolífera, mercado de trabalho e nível de dependência da mão de obra exógena nos municípios produtores de petróleo da Bacia de Campos, RJ. Revista Brasileira de Estudos Urbanos e Regionais, v. 17, n. 1, pp. 123-143.

Texto recebido em 26/maio/2017

Texto aprovado em 4/set/2017 